\title{
Rinitis micótica crónica en un canino Rottweiler: hallazgos histopatológicos
}

\author{
Ricardo Balaguera ${ }^{1}$ \\ ${ }^{1}$ Medico Veterinario MSc. Docente Universidad Antonio Nariño, Bogotá, Colombia. \\ Correspondencia: ricardo.balaguera@uan.edu.co \\ Recibido: 27-09-07 / Aceptado: 06-10-07
}

Resumen

Se reporta el caso de una rinitis crónica micótica en un ejemplar canino Rottweiler. Se ilustran las lesiones histológicas, los hallazgos microbiológicos y se discuten algunos elementos de diagnóstico y la importancia del estudio histopatológico en los procesos de rinitis crónica.

Palabras claves: Aspergillus sp., histiocitos, Moraxella sp., mucosa nasal, neoplasia, rinitis crónica mitótica.

\begin{abstract}
A case of chronic mycotic rhinitis Rottweiler is reported. The histological damages and the microbiological findings are illustrated. Some elements of diagnosis and the importance of histopathological diagnoses in the process of chronic rhinitis are discussed.

Key words: Aspergillus sp., chronical mytotic rinitis, histiocites, Moraxella sp., nasal mucose, neoplasia

\section{Introducción}

La etiología de las rinitis en los caninos es variada, incluye, por lo general, virus, bacterias, hongos, neoplasias y cuerpos extraños. Se ha reportado una mayor predisposición en razas de cabeza larga y estrecha como el pastor Alemán y en animales que habitan en apartamentos (1). Un estudio retrospectivo de enfermedades nasales persistentes en 42 caninos mostró que de un 91\% de los casos con diagnóstico definitivo un 33\% fueron neoplasias, $24 \%$ rinitis inflamatoria, $10 \%$ enfermedad periodontal, $7 \%$ aspergilosis y $7 \%$ cuerpos extraños (2).

Todas estas etiologías pueden tener una presentación clínica similar, lo cual hace necesario contar con herramientas de diagnóstico confiables para un tratamiento efectivo. La característica morfológica principal de la

Aspergilosis nasal es una lesión crónica necrotizante o granulomatosa con exudado copioso que contiene abundantes hifas fúngicas necróticas. La proliferación de hongos se produce por previas lesiones de la mucosa o por depresión de la respuesta inmune (3).

\section{Materiales y métodos}

En el laboratorio de histotecnia de la Universidad Antonio Nariño se recibieron varios fragmentos irregulares de tejidos fijados en formol tamponado al 10\%, estos fragmentos correspondían a un material de biopsia y fueron enviados con fines de diagnóstico. La evaluación macroscópica mostró al corte un color pardo rojizo y una consistencia elástica.
\end{abstract}


El resumen de la historia clínica reporta: paciente canino, macho de la raza Rotweiller, de 2 años y 9 meses de edad. El signo principal fue descarga nasal y epistaxis durante aproximadamente 3 meses. Por rinoscopia se diagnosticó un proceso inflamatorio crónico. Estudios bacteriológicos del exudado aislaron Moraxella sp y Staphylococcus sp. Sin embargo la terapia con antibióticos no fue efectiva. Posteriormente se realizó una citología de la zona afectada, la cual determinó un diagnóstico presuntivo de carcinoma nasal. El Veterinario clínico decidió realizar un estudio histopatológico del caso y obtiene quirúrgicamente unas masas que describe como amorfas y blanquecinas que luego envía para su análisis. Las muestras se procesaron según la técnica de inclusión en parafina, coloreándose con hematoxilina-eosina ( $\mathrm{H} \mathrm{y}$ E) y con ácido periódico de Schiff (PAS).

\section{Resultados}

En la evaluación microscópica se encontró una mucosa nasal con infiltrado mononuclear donde predominan células plasmáticas e histiocitos. Además muestra notoria hiperplasia de nódulos linfoides e hipertrofia de la túnica media de varias arterias y arteriolas, Figura 1. También se observaron varias masas de tejido indeterminado que muestran abundantes estructuras micóticas (hifas tabicadas), Figuras 2 y 3.

Los tejidos con estructuras micóticas fueron teñidos con ácido periódico de Schiff (PAS), con la cual se resaltaron las estructuras del agente etiológico. Se recomendó realizar aislamiento micótico para clasificar el agente etiológico, identificando Aspergillus sp.

\section{Discusión}

Entre las herramientas de diagnóstico para los casos de rinitis crónica se encuentran la tomografía computarizada, la radiología y la inmunología $(4,5)$. Sin embargo, a excepción de la tomografía computarizada, no siempre se puede con estas técnicas llegar al diagnóstico específico $(5,6)$. En nuestro medio los recursos son limitados y por lo tanto es importante

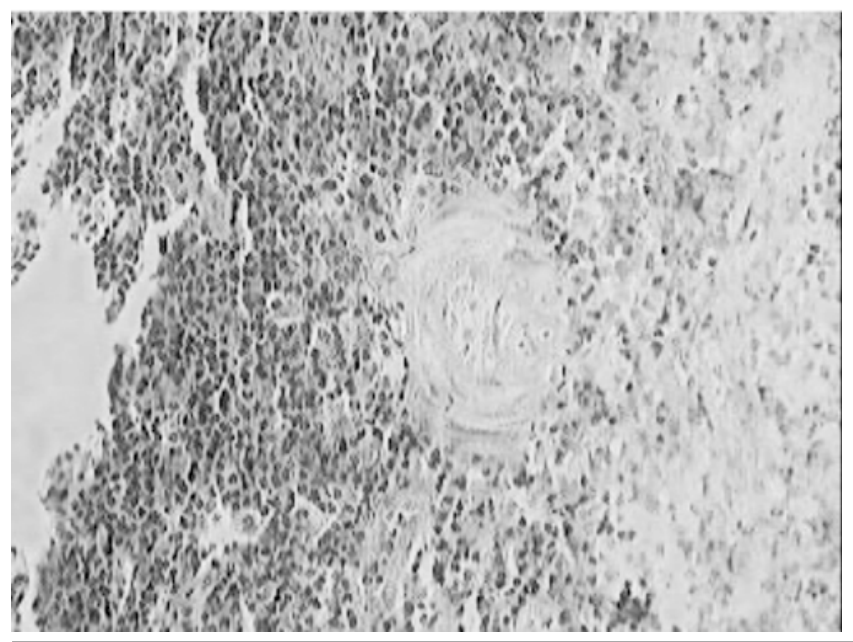

Figura 1. Mucosa nasal con infiltrado mononuclear donde predominan células plasmáticas e histiocitos. Hipertrofia de la túnica media de varias arterias y arteriolas.10x. $\mathrm{H}$ y $\mathrm{E}$.

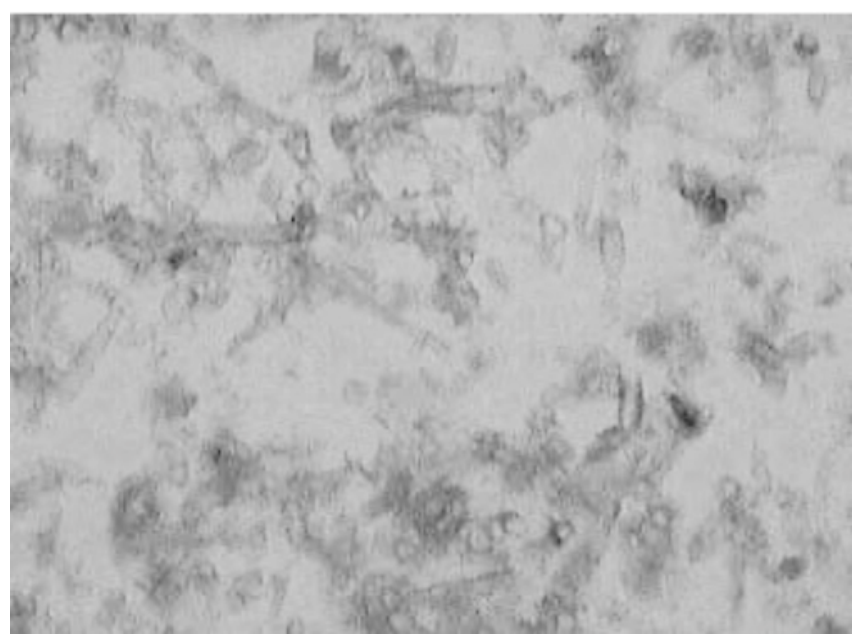

Figura 2. Estructuras micóticas, hifas tabicadas en cortes transversales y longitudinales. 100x. H y E.



Figura 3. Corresponde a la muestra de la figura 2 con coloración de PAS 100x 
decidirse por técnicas confiables pero económicas para realizar un diagnóstico acertado y rápido. Un diagnóstico con poca sensibilidad como la citología o la presencia de complicaciones secundarias bacterianas, pueden desviar la atención de la etiología específica y plantear terapéuticas erradas que complican la evolución del paciente y aumentan los costos a los propietarios.

El diagnóstico histopatológico y los estudios microbiológicos, apoyados en una correcta correlación clinico patológica, siguen siendo ayudas importantes en la práctica clínica veterinaria. Es necesario identificar la causa de las rinitis rápidamente para evitar las complicaciones clínicas que son frecuentes en estos casos, de igual forma, aunque se cuenta con tratamientos convencionales con variados antimicóticos como: clotrimazole, enilconazole, itraconazole y amphotericin B entre otros $(6,7)$. Estos tratamientos han requerido modificaciones con técnicas de infusión invasivas y no invasivas debido a resultados adversos en varios pacientes (8).

\section{Agradecimientos}

Al Laboratorio de Ciencias Básicas de la Universidad Antonio Nariño por el procesamiento histotécnico de las muestras y el proceso de captura de imágenes histológicas. NOV

\section{Referencias}

1. Mortellaro C, Francia P, Caretta G. Aspergillus fumigatus, the causative agent of infection of the frontal sinuses and nasal hambers of the dog. Mycoses. 1989;32:327-335.

2. Tasker S, Knottenbelt C, Munro E, Stonehewer J, Simpson J, Mackin A. A etiology and diagnosis of persistent nasal disease in the dog: a retrospective study of 42 cases. J Small Anim Pract. 1999;40:473-478.

3. Ferreira D. Patología Veterinaria. Ed. Universidad de Antioquia. Medellín 2003

4. Codner E, Lurus A, Miller J, Gavin P, Gallina A, Barbee D. Comparison of computed tomography with radiography as a noninvasive diagnostic technique for chronic nasal disease in dogs. J. Am. Vet. Med. Assoc. 1993; 202:1106-1110.

5. Russo M, Lamb Cr, Jakovljevic S. Distinguishing rhinitis and nasal neoplasia by radiography. Vet Radiol Ultrasound. 2000;1:118-124

6. Willard M, Radlinsky M. Endoscopic examination of the choanae in dogs and cats: 118 cases (1988-1998). J Am Vet Med Assoc. 1999;215:1301-1305.

7. Mathews K, Koblik P, Richardson E, Davidson A, Pappagianis D, Ray J, White R, Lascelles B. Computed tomographic assessment of noninvasive intranasal infusions in dogs with fungal rhinitis. Vet Surg. 1996;25:309-319.

8. Bray J, White R, Lascelles B. Treatment of canine aspergillosis with a new non-invasive technique. Failure with enilconazole. J Small Anim Pract. 1998;39:223-226.
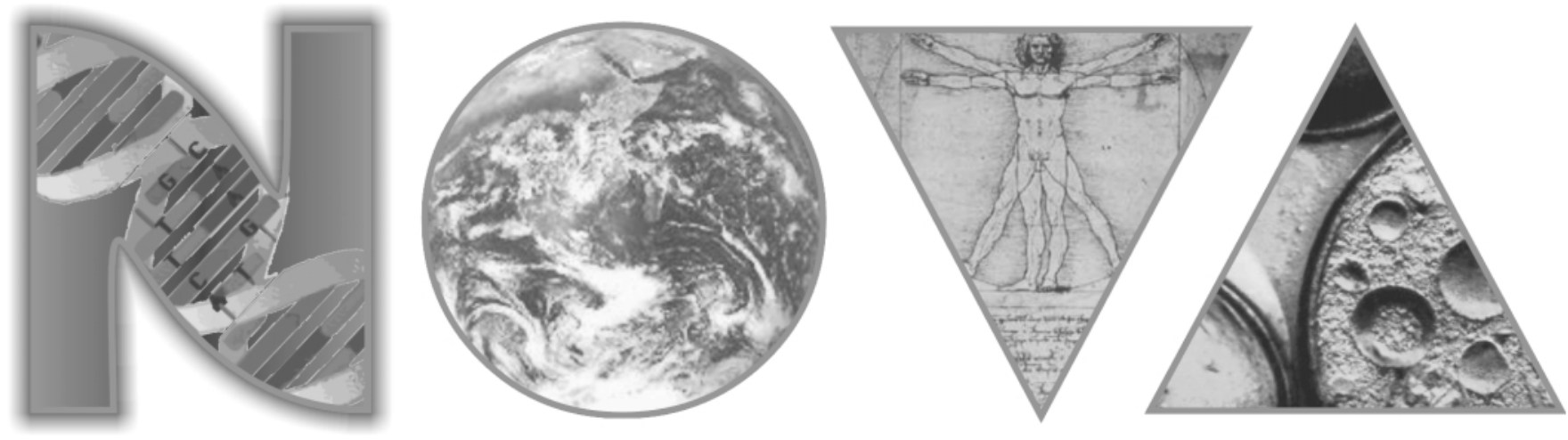